\title{
The relationship of frequent tropical cyclone activities over the western North Pacific and hot summer days in central-eastern China
}

\author{
Zhong Zhong $^{1,2}$ (D) $\cdot{\text { Xian } \mathrm{Chen}^{3} \cdot \text { Xiu-Qun } \mathrm{Yang}^{2} \cdot \mathrm{Yao} \mathrm{Ha}^{1} \cdot \text { Yuan Sun }}^{1}$ \\ Received: 15 October 2018 / Accepted: 20 May 2019 / Published online: 29 May 2019 \\ (C) The Author(s) 2019
}

\begin{abstract}
Tropical cyclones (TCs) formed over the western North Pacific (WNP) often make landfalls over East Asia and Southeast Asia, causing strong winds and torrential rain in the coastal countries. However, they also bring cool weather on hot summer days and mitigate drought impacts. The present study demonstrates that TC activities over the WNP can strongly modulate extreme summer weather events in eastern mainland China, i.e., frequent TC activities would indirectly lead to more hot days in central-eastern China along the lower and middle reaches of Yangtze River, besides compensating the decreasing of hot days induced by the direct impact of TCs. Such indirect impact is largely determined by the feedback effect of TCs on pressure system, especially on the western Pacific subtropical high, resulting in an abnormal anticyclonic circulation band that dominates a large area from central-eastern China to the Pacific Ocean to the east of Japan in the middle and lower troposphere.
\end{abstract}

\section{Introduction}

Tropical cyclones (TCs) over the western North Pacific (WNP) are among the most devastating weather events that affect East Asia and Southeast Asia. Landfalling TCs have substantial socio-economic impacts. Therefore, the TC occurrence frequency and TC tracks are a topic of profound societal significance and intense scientific interest (Mendelsohn et al. 2012).

Heat waves that occurred in recent years on both regional and global scales have attracted great attention (Easterling et al. 2000; Grumm 2011) since extreme high-temperature events are meteorological disasters. In the context of global warming, the occurrence frequency of extremely hot weather

Zhong Zhong

zhong_zhong@yeah.net

1 College of Meteorology and Oceanography, National University of Defense Technology, No. 60, Shuanglong Road, Nanjing 211101, China

2 Jiangsu Collaborative Innovation Center for Climate Change, School of Atmospheric Sciences, Nanjing University, Nanjing 210093, China

3 China Aerodynamics Research and Development Center, Mianyang 621000, China and heat waves demonstrates a rising trend (IPCC 2007; Coumou and Rahmstorf 2012; Hu et al. 2017). Previous studies indicated that high-temperature events often occur under the joint effect of large-scale circulation and local physical processes (Diffenbaugh et al. 2005; Miralles et al. 2014; Horton et al. 2015). It is found that high-temperature events largely occur in clear days when radiative heating is strong, thereby the number of rainy days in the summer is highly negatively correlated with the number of hot days on the interannual time scale (Ding et al. 2010).

The western Pacific subtropical high (WPSH) is one of the major synoptic and climate systems that affects temperature change and extreme high-temperature events in the summer over eastern China (Liang and $\mathrm{Wu} 2015$ ). TC activities in the WNP have significant impacts on regional weather and climate systems like the WPSH over East Asia-WNP (EA-WNP) region (Nitta 1987; Zhong and $\mathrm{Hu}$ 2007; Sun et al. 2015; Chen et al. 2017). One good example is that TC-induced precipitation accounts for a large proportion of the total precipitation in most areas of southeastern China (Ren et al. 2002) and makes influence on the spatiotemporal variations in typhoon season rainfall in south China (Lee et al. 2010; Chen et al. 2012). In the coastal region of southeastern China, it can be more than $500 \mathrm{~mm}$ per year, which accounts for $20 \sim 40 \%$ of the total annual precipitation there (Ren et al. 2006; Zhang et al. 
2013). Those imply possible fewer hot days in southeastern China in the years when more TCs form over the WNP. However, whether this is true still remains an unanswered question, since it was found that the influence of TCs may affect heat waves in Southeastern Australia indirectly (Parker et al. 2013) and the persistent heat wave periods occurred in South China were related to the sinking motion of upper outflow of TC (Fang and Jian 2011). The current work aims to investigate the impact of TCs on extreme hot events in eastern China. Results presented here will help to reveal the abnormal pattern of hot days induced by TC activities and the possible mechanism.

The data and methods used in the present study are described in Section 2. Results of composite analysis and numerical experiments are presented in Section 3. Conclusions and discussion are given in Section 4.

\section{Data and Methods}

The TC best-track data is obtained from the Regional Specialized Meteorological Center (RSMC) of Japan Meteorological Agency (JMA) (http://www.jma.go.jp/jma/ jma-eng/jma-center/rsmc-hp-pub-eg/RSMC_HP.htm). The data includes TC name, TC position in latitude and longitude, TC center pressure, and maximum sustained winds at 6-h intervals. Daily surface air temperature, precipitation, and sunshine duration collected at 2474 weather stations in mainland China are provided by the National Meteorological Information Center of China Meteorological Administration. Atmospheric circulation regimes are derived from the NCEP/NCAR reanalysis dataset (Kalnay et al. 1996).

The 50 summers (June-August) from 1961 to 2010 are chosen for TC statistics and large-scale environment field analysis over EA-WNP in active and inactive TC years. Among the selected summers, according to the TC genesis frequency, the 10 most active TC years (AY) are determined to be $1965,1966,1967,1971,1972,1978,1981,1992,1994$, and 2004, and the 10 least active TC years (IY) are identified to be $1969,1975,1977,1979,1980,1983,1998,2007,2008$, and 2010.

The composite method is employed to highlight different features of sunshine duration (SSD), surface air temperature (SAT), precipitation (PRE), hot days (HDs), and regional atmospheric circulation between AY and IY. Here, a HD is defined as the day with daily maximum temperature is equal to or greater than $35^{\circ} \mathrm{C}$ (Ding et al. 2010).

To verify the results of diagnostic analysis, numerical experiments for the simulation of the super typhoon Solik (2013) were conducted using the non-hydrostatic model WRFV3.4.

\section{Results}

\subsection{Composite analysis}

The statistical analysis shows that there are large differences in TC genesis frequency and TC track between AY and IY. In total, there were $161 \mathrm{TCs}$ for the $10 \mathrm{AYs}$ while there were only 72 TCs for the 10 IYs, less than half of that in AYs. After their genesis, most TCs moved northwestward before they turned northward and affected the middle to high latitudes. In the 10 AYs, 41 TCs made landfall and 67 TCs reached north of $35^{\circ}$ $\mathrm{N}$. In contrast, only $27 \mathrm{TCs}$ made landfall and $19 \mathrm{TCs}$ reached north of $35^{\circ} \mathrm{N}$ in the $10 \mathrm{IYs}$.

Figure 1 presents TC genesis frequencies and track densities calculated over $5^{\circ} \times 5^{\circ}$ grids and averaged for the 10 summers of active and inactive TC years. Their differences are also displayed. Three large TC genesis centers can be found in the WNP, i.e., over the northern South China Sea, over the Pacific Ocean to the east of Philippine and near the Mariana Islands in active TC years. The maximum TC genesis frequency reaches 1 /per year at all the three centers (Fig. 1a). In the inactive TC years, however, the maximum TC genesis frequency center was located near the Mariana Islands with the maximum value of only $0.4 /$ year (Fig. $1 b$ ), which is less than half of the TC genesis frequency in active TC years. Except over the Bashi Channel and some areas to the north of New Guinea Islands, TC genesis frequency in active TC years was always larger than that in inactive TC years. Centers of the largest difference are consistent with the maximum TC genesis centers in the AYs with the maximum difference greater than 0.6/year at all the centers (Fig. 1c).

Looking at the TC track density, two maximum centers can be found at the northern South China Sea and the Pacific Ocean to the east of Taiwan in AYs with the maximum values of 19 times/year and 21 times/year, respectively (Fig. 1d). In IYs, however, the largest track density was located at the Bashi Channel with the maximum value of 11 times/year (Fig. 1e). Over the entire EA-WNP region, the TC track density in AYs was always larger than that in IYs. Except for the ocean area to the east of the Bashi Channel, spatial distribution of the difference in TC track density between the active and inactive TC years was also consistent with that of the TC track density in the active TC years and the largest difference is about 9 times/year (Fig. 1f). Therefore, large differences can be found not only in the TC genesis frequency and location but also in statistical TC track density between AYs and IYs, which result in large differences in circulation and precipitation as well as summertime weather and climate features over EA-WNP.

Figure 2 displays summertime averaged SSD, PRE, SAT, and HDs for AYs and IYs and their differences over mainland China. It can be found that the average SSD from southern North China to the south of the lower and middle reaches of 
Fig. 1 Summertime averaged TC genesis frequency (left) and TC track density (right) over the western North Pacific in $5^{\circ} \times 5^{\circ}$ grids for active TC years $(\mathbf{a}, \mathbf{d})$, inactive TC years $(\mathbf{b}, \mathbf{e})$, and differences between active and inactive TC years $(\mathbf{c}, \mathbf{f})$
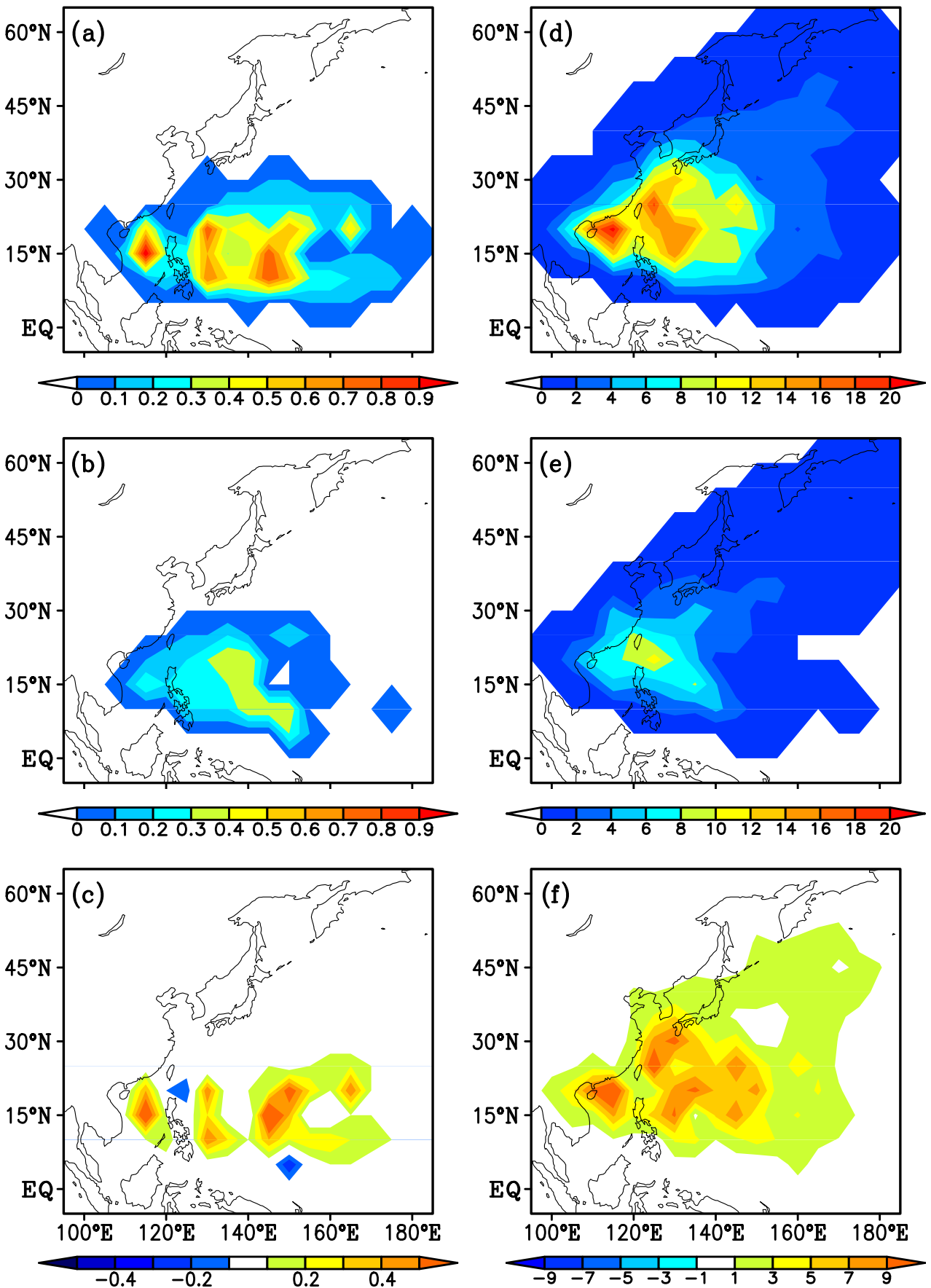

the Yangtze River (LMRYR) was about 6-8 $\mathrm{h} /$ day in AY but only 5-7 h/day in IY. In other areas, the average SSD in AYs was nearly identical to that in IYs, and SSD basically increased with latitudes (Fig. 2a, b). Large differences in SSD between AYs and IYs covered central-eastern China centered along the LMRYR. Two maximum difference centers are found in the Yangtze River Delta and inland Hunan province, respectively, with maximum difference greater than $1.8 \mathrm{~h} /$ day in both centers (Fig. 2c).

The spatial distribution of summer PRE indicates that in both AYs and IYs, PRE in eastern mainland China gradually decreased from southeast to northwest (Fig. 2d, e), while the largest difference in PRE between AYs and IYs was still centered along the LMRYR (Fig. 2f) and PRE there in AYs was less than that in IYs. Therefore, although frequent TC activities in AYs could bring more precipitation to southeastern China during TC periods (Ren et al. 2002; Lee et al. 2010; Chen et al. 2012), the feedback of TC activities on the atmospheric circulation might lead to reduced precipitation in central-eastern China before and after the passing of TCs. In addition, precipitation decreases centered along the LMRYR in AYs were consistent with longer summertime SSD there 

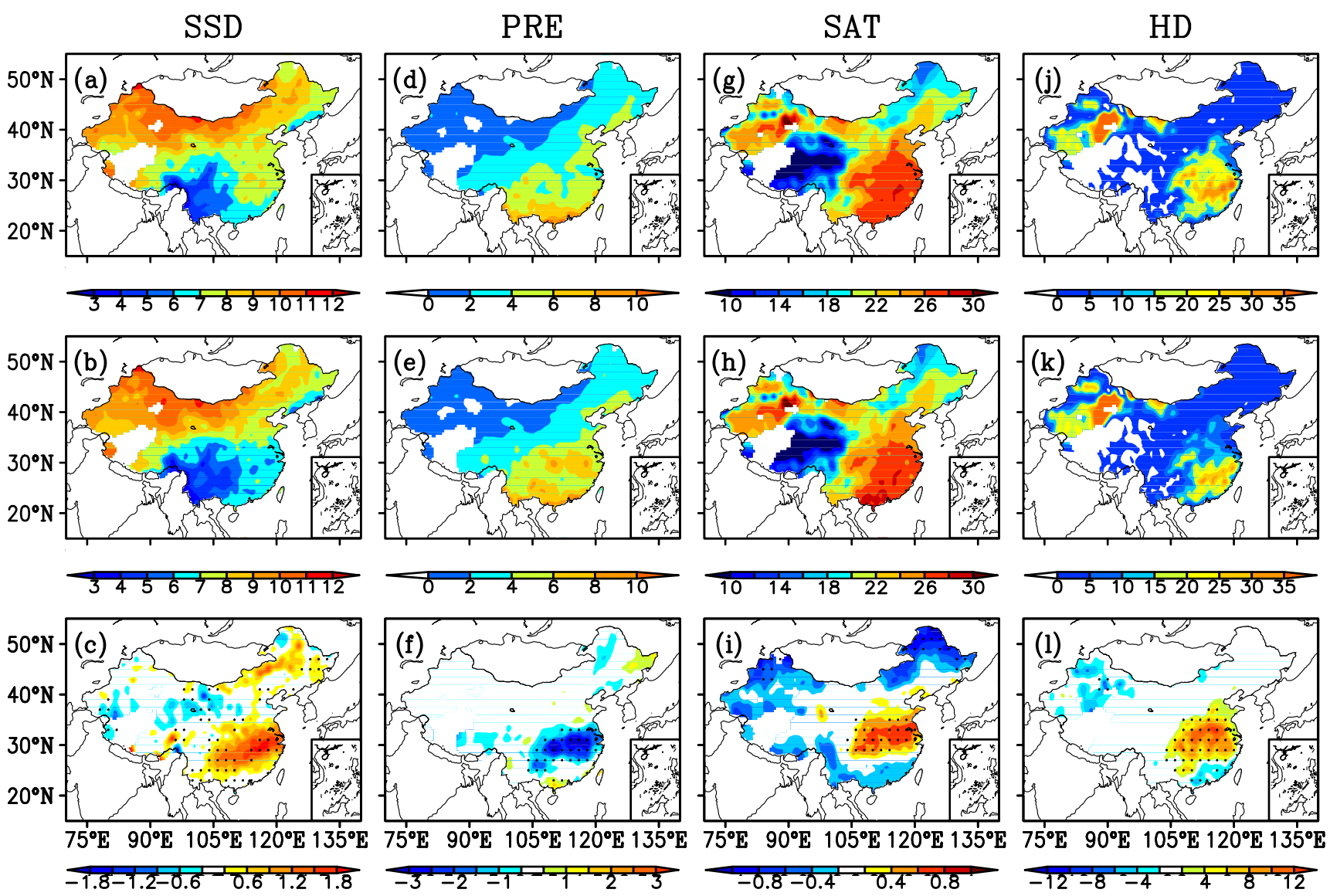

Fig. 2 Distributions of mean sunshine duration (SSD, unit: $\mathrm{h}$ day ${ }^{-1}$ ), precipitation (PRE, unit: $10^{2} \mathrm{~mm}$ ), surface air temperature (SAT, unit: ${ }^{\circ} \mathrm{C}$ ), and hot days (HD, unit: day ) in mainland China in the summer for

(Fig. 2c). However, precipitation in the coastal region of southern China that was under the strongest influence of TCs in AYs was slightly more than that in IYs (Fig. 2f).

Longer SSD and less precipitation both can result in higher SAT in the summer, and thereby increase the occurrence frequency of high-temperature events (Ding et al. 2010; Soon et al. 2011; Qian et al. 2012). Figure $2 \mathrm{~g}$ and $\mathrm{h}$ exhibit clearly that summertime average SAT was higher than $26{ }^{\circ} \mathrm{C}$ over most areas to the south of the Huaihe River in eastern mainland China in both AYs and IYs. In AYs, the summertime average SAT ranged between $26-28{ }^{\circ} \mathrm{C}$ in southeastern China and higher than $28^{\circ} \mathrm{C}$ in some inland provinces (Fig. $2 \mathrm{~g}$ ). In IYs, however, the average SAT was lower than $26^{\circ} \mathrm{C}$ in southeastern China but higher than $28^{\circ} \mathrm{C}$ in parts of southern China (Fig. 2 h). Differences in summertime SAT between AYs and IYs suggest that the SAT in AYs was also significantly higher than that in IYs in central-eastern China along the LMRYR, and the largest difference could be more than 0.6 ${ }^{\circ} \mathrm{C}$. In the coastal region of southern China, however, SAT in AYs was lower than that in IYs with the maximum difference of about $-0.4{ }^{\circ} \mathrm{C}$ (Fig. 2i). active TC years $(\mathbf{a}, \mathbf{d}, \mathbf{g}, \mathbf{j})$, inactive TC years $(\mathbf{b}, \mathbf{e}, \mathbf{h}, \mathbf{k})$, and differences between active and inactive TC years $(\mathbf{c}, \mathbf{f}, \mathbf{i}, \mathbf{l})$, where the dotted areas represent significant at the $95 \%$ confidence level or higher

It is expected that the average HD distribution is similar to that of SAT, since the occurrence frequency of extreme hightemperature events increases in response to the increase in SAT (Alexander et al. 2006; IPCC 2007). As shown in Fig. $2 \mathrm{j}$ and $\mathrm{k}$, the summertime average HD in AYs was more than 15 days in central and southeastern China, and HD longer than 30 days occurred to the south of LMRYR with the maximum of more than 35 days (Fig. 2j). In IYs, the areas with average summer HD longer than 15 days were largely found to the south of LMRYR, and the maximum HD was 32 days (Fig. 2 k). Again, the differences in summertime average HD between AYs and IYs were positive in central-eastern China along the LMRYR, with the maximum 14 days in central Anhui province. On the contrary, the negative maximum of -3 days was found in the coastal region of southern China (Fig. 2 1).

In brief, frequent TC activities over the WNP in the summer could lead to increases in SSD as well as SAT and decreases in precipitation over central-eastern China along LMRYR, which prolonged HD there and gave rise to more high-temperature events, while SAT and HD both decreased in AYs only in the coastal region of southern China. 
Figure 3 exhibits the summertime mean circulation patterns at $500 \mathrm{hPa}$ and $850 \mathrm{hPa}$ over EA-WNP for AYs and IYs. Their differences are also displayed. As shown in Fig. 3 a and b, the average WPSH intensity was weaker in AYs than in IYs, since the WPSH is usually weakened by TC activities (Zhong and Hu 2007; Wang et al. 2010; Sun et al. 2014). The largest mean WPSH intensity could be greater than 588 dagpm in IYs but smaller than 588 dagpm in AYs. Specifically, the mean ridge line of the WPSH to the west of $130^{\circ} \mathrm{E}$ was located in southern China in AYs, whereas it was situated in the coastal area of southern China in IYs, which was further south than that in AYs. Moreover, the pressure system over the entire EA-WNP was also weaker in AYs than in IYs (Fig. 3c). As a result, a zonal band with relatively small decrease of geopotential height appeared, which extended from central-eastern China to the east to Japan in the Pacific with the center located along $35^{\circ} \mathrm{N}$ and a width of 20 degrees latitude (Fig.3c). Large geopotential height decrease bands were also found to the south and north of the band mentioned above, with centers located at the northern South China Sea and over the continent near the Okhotsk Sea, respectively. At $850 \mathrm{hPa}$, the WPSH in AYs was also weaker than that in IYs. For example, the 148 dagpm contour within $20^{\circ} \mathrm{N}-25^{\circ} \mathrm{N}$ was located to the east of Taiwan in AYs (Fig. 3d) but it extended westward and reached southeastern mainland China in IYs (Fig. 3e), and the geopotential height difference at $850 \mathrm{hPa}$ between $\mathrm{AYs}$ and IYs was similar to that at $500 \mathrm{hPa}$. Again, a zonal band with relatively small decreases existed at $500 \mathrm{hPa}$ and relatively larger geopotential height differences occurred to the south and north of this zonal band (Fig. 3f). Therefore, it could be concluded that TC activities over the WNP have similar impacts on the middle and lower troposphere, where the mean flow displayed a quasi-barotropic structure. Corresponding to such circulation changes in the middle and lower troposphere, the East Asian upper level subtropical jet shifted poleward in AYs compared to that in IYs (Chen et al. 2017). In particular, although the pressure system in EA-WNP was weaker in AYs than in IYs, decreases in geopotential height along the zonal band from central-eastern China to the Pacific Ocean to the east of Japan were smaller than those to the south and north of this band, resulting in a significant quasi-zonal anomalous anticyclonic circulation band in this region (Fig. 3c, f), which is favorable for the maintenance of high surface temperature there. Yet, the abnormal anticyclonic circulation band actually corresponded to areas where the geopotential height decreased, suggesting that under the influence of TC activities, ageostrophic divergent flow was dominant in this zonal band.

The spatial patterns of vorticity and vertical velocity differences between AYs and IYs averaged from $1000 \mathrm{hPa}$ to $500 \mathrm{hPa}$ are shown in Fig. 4. It can be seen that differences
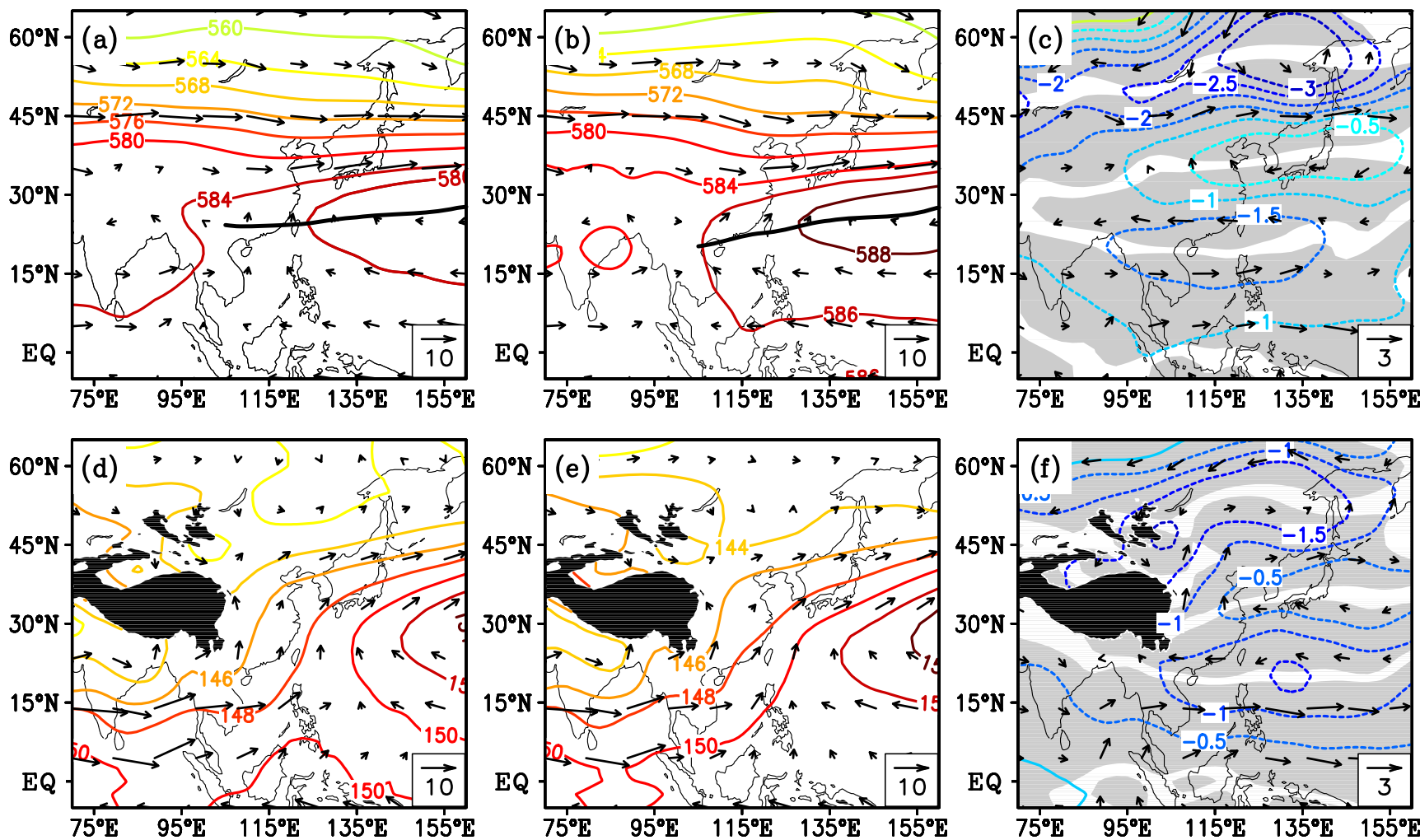

Fig. 3 Distributions of mean geopotential height (contours, unit: dagpm) and wind fields (vectors, unit: $\mathrm{m} \mathrm{s}^{-1}$ ) in the summer at $500 \mathrm{hPa}(\mathbf{a}, \mathbf{b}, \mathbf{c})$ and $850 \mathrm{hPa}(\mathbf{d}, \mathbf{e}, \mathbf{f})$ in $\mathrm{AY}(\mathbf{a}, \mathbf{d})$, IY $(\mathbf{b}, \mathbf{e})$, and the differences between $\mathrm{AY}$ and IY $(\mathbf{c}, \mathbf{f})$, where the black lines in (a) and (b) represent the mean

ridge line of WPSH, and the black shading areas in (d), (e), and (f) indicate the Tibetan Plateau, and the gray shading areas in (c) and (f) represent significant at the $95 \%$ confidence level or higher for zonal winds 

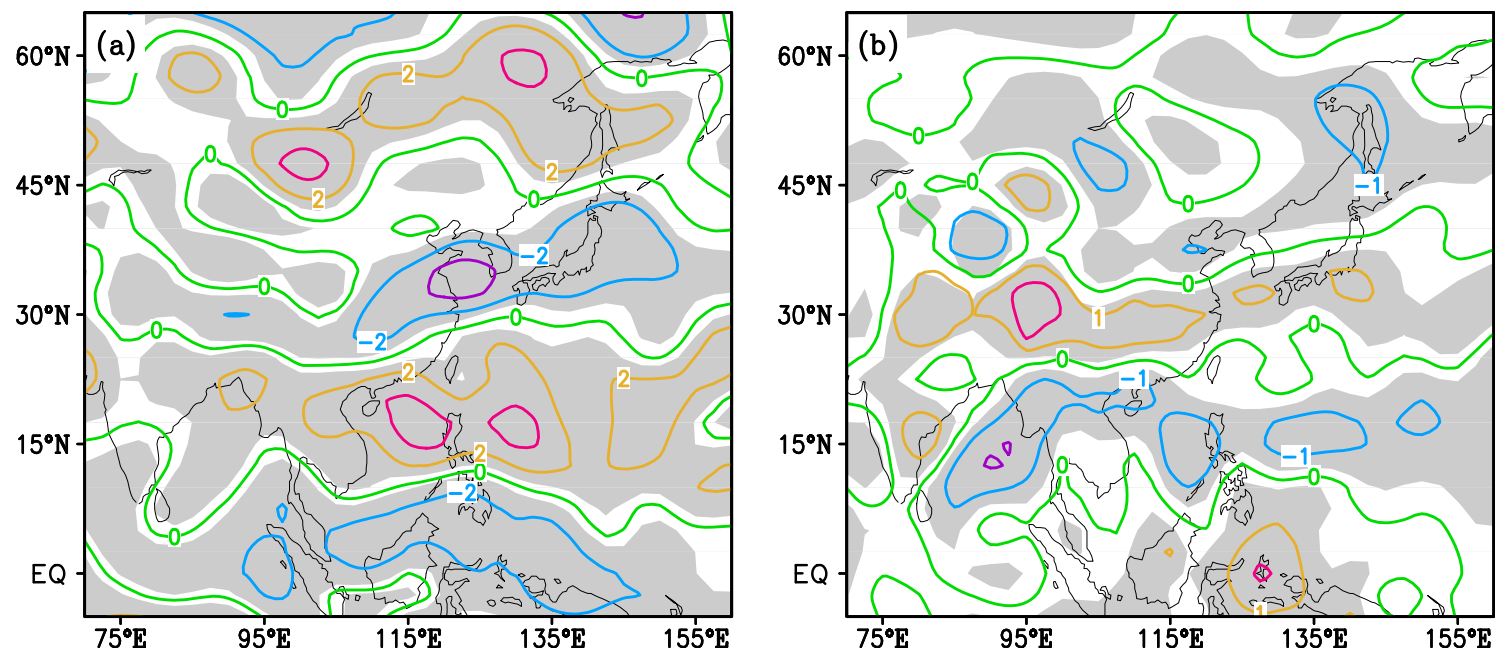

Fig. 4 Distributions of a vorticity difference (unit: $10^{-6} \mathrm{~s}^{-1}$ ) and $\mathbf{b}$ vertical velocity difference (unit: $10^{-4} \mathrm{hPa} \mathrm{s}{ }^{-1}$ ) between active and inactive TC years averaged from 1000 to $500 \mathrm{hPa}$

in the vertical component of vorticity and vertical velocity well-matched differences in horizontal circulation between AYs and IYs basically. Corresponding to the anticyclonic zonal band shown in the circulation differences (Fig. 3c, f), the vorticity difference was negative (Fig. 4a) and descending motion intensified (Fig. 4b) in the middle and lower troposphere over central-eastern China. Such differences indicate that convection was suppressed and solar radiation on the surface increased in AYs compared to that in IYs. Meanwhile, SAT increased subsequently and the occurrence frequency of high-temperature events also increased. In contrast, the difference in vorticity was positive while ascending motion intensified in the coastal region of southeastern China, which was favorable for the development of convection and precipitation with decreased SSD and lower SAT, leading to the decrease in high-temperature events there in AYs.

In order to further demonstrate that TC activities over the WNP indeed have feedback effects on large-scale circulation, circulations at $500 \mathrm{hPa}$ during the periods of TC occurrence (4561 times) and those during the TC-free periods (2799 times) are extracted from the 6-h interval reanalysis data for the 20 summers of AYs and IYs. Composite analysis is then conducted over the EA-WNP region (Fig. 5). As shown in Fig. 5a, during the periods of TC occurrence, the 586-dagpm contour could only reach the coastal region of southeastern China and the WPSH ridge line at $120^{\circ} \mathrm{E}$ was located at around $26.5^{\circ} \mathrm{N}$, which was more than $2^{\circ}$ north of the multiyear summertime mean latitude of $24.3^{\circ} \mathrm{N}$ (Wu et al. 2002) and even further north than that in AYs shown in Fig. 3a. During the TC-free periods, the 586-dagpm contour extended westward, reaching the Indochina Peninsula, and the WPSH ridge line at $120^{\circ} \mathrm{E}$ was located at around $21^{\circ} \mathrm{N}$ (Fig. 5b) to the south of the multi-year mean latitude and even slightly south than that in IYs shown in Fig. 3b. Therefore, TC activities actually lead to a weakened and poleward shifted WPSH, which agrees with the results of sensitivity experiments conducted by Sun et al. (2014). Figure 5 c shows clearly that the difference in circulation at $500 \mathrm{hPa}$ between TC occurrence periods and TC-free periods exhibits a cyclonic circulation to the south of $25^{\circ} \mathrm{N}$ with the center located near the Bashi
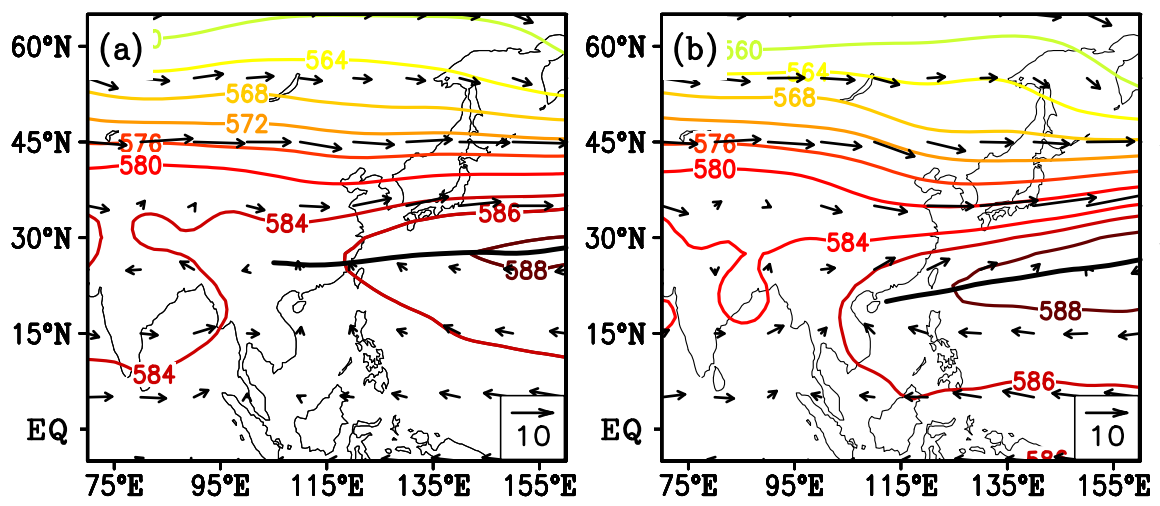

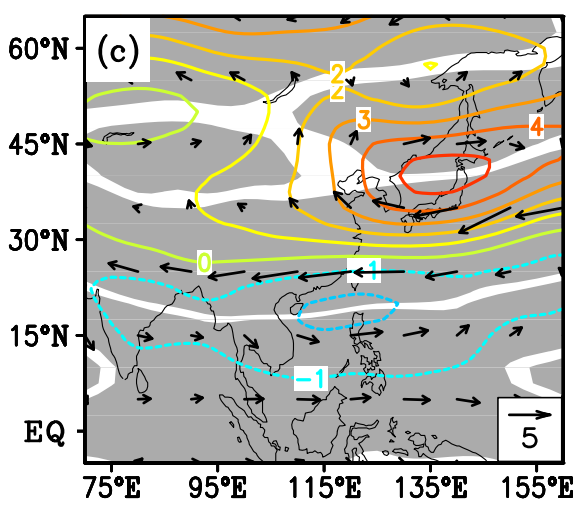

differences, where the black lines in (a) and (b) represent the mean ridge line of WPSH and the gray shading areas in (c) represent significant at the $95 \%$ confidence level or higher for zonal wind. 
Fig. 6 Model domain (fanshaped area), Solik (2013) track observation (red dot) and simulation (black circle) by control run (CR) from 0000 UTC 8 July to 1200 UTC 14 July 2013 at $6 \mathrm{~h}$ interval

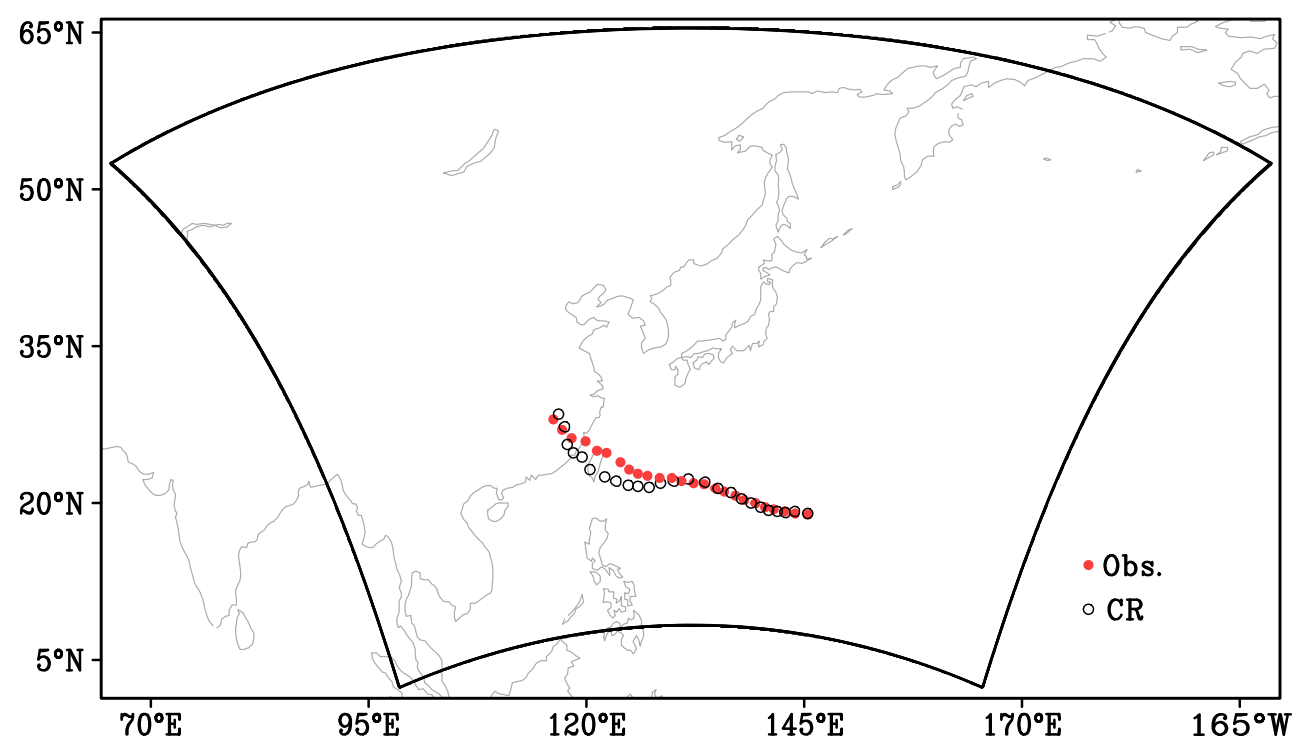

Channel and northern South China Sea, and an anticyclonic circulation to the north of $25^{\circ} \mathrm{N}$ with the center located over the Sea of Japan. Such a distribution of cyclonic and anticyclonic circulation differences between TC occurrence and TCfree periods is somewhat similar to that between AYs and IYs shown in Fig. 3c.

It is worth noting that, similar to the situation that the geopotential height differences between AYs and IYs are consistent in the middle and lower troposphere (Fig. 3c, f), the differences in the summer circulation between TC occurrence periods and TC-free periods at $850 \mathrm{hPa}$ (Figure omitted) also are similar to that at $500 \mathrm{hPa}$ (Fig. 5c). This indicates that the impacts of TC activities on regional circulation show a quasibarotropic feature in the middle and lower troposphere. Therefore, the frequent TC activities indeed have feedback effects on large-scale pressure system. In response to such kind of feedback, the WPSH shifts northward, leading to the formation of abnormal divergence and anticyclonic circulation band over central-eastern China along the LMRYR, which is favorable for the maintenance of clear sky there and leading to net increasing in $\mathrm{HD}$, besides compensating the decreasing in HD induced by the direct impact of TCs. In addition, the HDs in South Korea and southern Japan would also have the same experiences as in central-eastern China, since those areas are in the same abnormal anticyclonic band induced by frequent TC activities in summer.

\subsection{Numerical experiment}

Two experiments for the simulation of Typhoon Solik (2013) that covered its lifetime from 0000 UTC 8 July to 1200 UTC 14 July 2013 were conducted with the WRF model. For the control run (hereafter $\mathrm{CR}$ ) of Solik simulation, the center of the model domain is located at $\left(37^{\circ} \mathrm{N}, 132^{\circ} \mathrm{E}\right)$ with a grid spacing of
$20 \mathrm{~km}$ and $435 \times 335$ horizontal grid points. The top of the model is set to $50 \mathrm{hPa}$ with 35 vertical levels. The initial and lateral boundary conditions are extracted from the NCEP/NCAR reanalysis data on global $1^{\circ} \times 1^{\circ}$ grids (https://doi.org/10.5065/ D6M043C6) at 6-h intervals. Important model physical schemes include the WSM 5-class microphysics scheme, the KainFritsch (New Eta) cumulus parameterization scheme, the RRTM long-wave radiation scheme, the (old) Goddard shortwave radiation scheme, the YSU planetary boundary scheme, and the Unified Noah land surface scheme, and the MoninObukhov similarity theory is applied to describe surface layer physics. Detailed descriptions of the WRF dynamics and physical schemes can be found in Skamarock et al. (2008).

The sensitivity run (hereafter SR) was conducted by removing the vortex of TC Solik from the first-guess large-scale field at the initial time, which is the first step of the so-called bogus technique (Christopher and Simon 2001), which is usually applied to investigate interactions between the TC activity and surrounding large-scale circulation (Zhong and $\mathrm{Hu} 2007$; Tang et al. 2013). Except for the TC vortex removal at initial time of the simulation, all other options in the SR are identical to those in CR.

Figure 6 shows the model domain, the observed Solik track and the track simulated in the control run (CR) from 0000 UTC 8 July to 1200 UTC 14 July 2013. Both observations and model outputs are at 6 -h intervals. The observed Solik track was well reproduced in the CR except during the period when it was passing over Taiwan. In the simulation, Solik made landfall at southern Taiwan while the observations show that it made landfall at northern Taiwan.

Compared to the simulation of Solik in the experiment SR, the simulation in CR shows an abnormal high surface temperature band extending from central China to South Korea and south Japan (Fig. 7), which is accompanied by an elongated 
Fig. 7 Distribution of surface air temperature difference between $\mathrm{CR}$ and SR averaged for simulation period (units: ${ }^{\circ} \mathrm{C}$ ), where the dotted areas represent significant at the $95 \%$ confidence level or higher

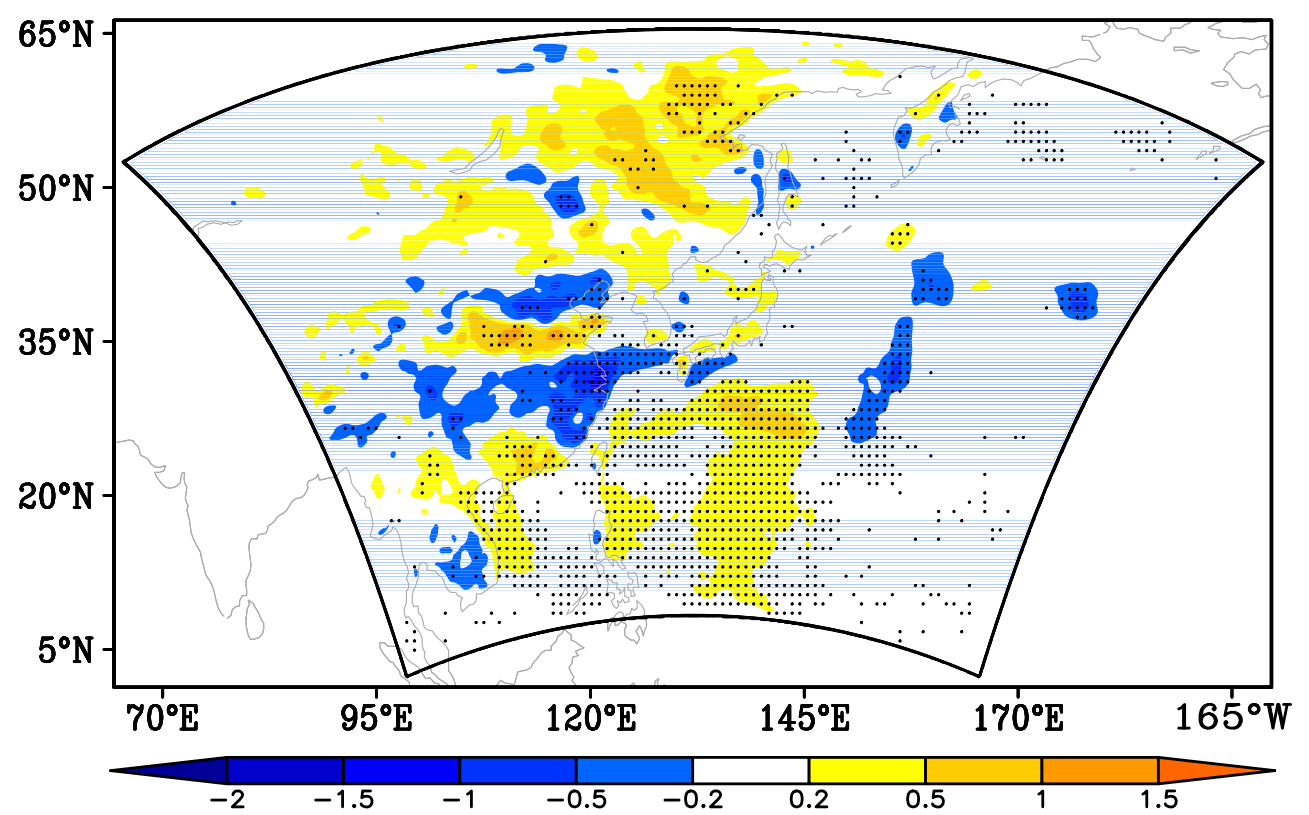

precipitation decreasing band (Fig. 8) similar to the differences between AYs and IYs. This suggests that the TC feedback does lead to zonal surface temperature and precipitation changes in some subtropical areas during its lifetime period. However, it should be pointed out that the latitudinal location of the abnormal high surface temperature and precipitation decrease in the simulation of $\mathrm{CR}$ is further north compared to the location of temperature and precipitation differences between AYs and IYs. This is because the differences between CR and SR simulations represent the differences with and without the TC vortex, and thus, the results are to some extent more consistent to the differences between TC occurrence period and TC-free period (Fig. 4c).

\section{Conclusions and discussion}

In the present study, composite analysis has been conducted to explore the large-scale circulation differences in the summers between TC active years and TC inactive years over the WNP. It is found that TC activities over the WNP can strongly influence extreme summer climate in eastern mainland China, and frequent TC activities would indirectly lead to more hot days in central-eastern China centered along the lower and middle reaches of the Yangtze River, and make up for the decrease in hot days induced by the direct impact of TCs. Moreover, this study reveals that the feedback effect of TCs on the WPSH plays an important role in the formation of an
Fig. 8 Distribution of accumulated precipitation amount difference (units: $\mathrm{mm}$ ) between $\mathrm{CR}$ and SR during simulation period

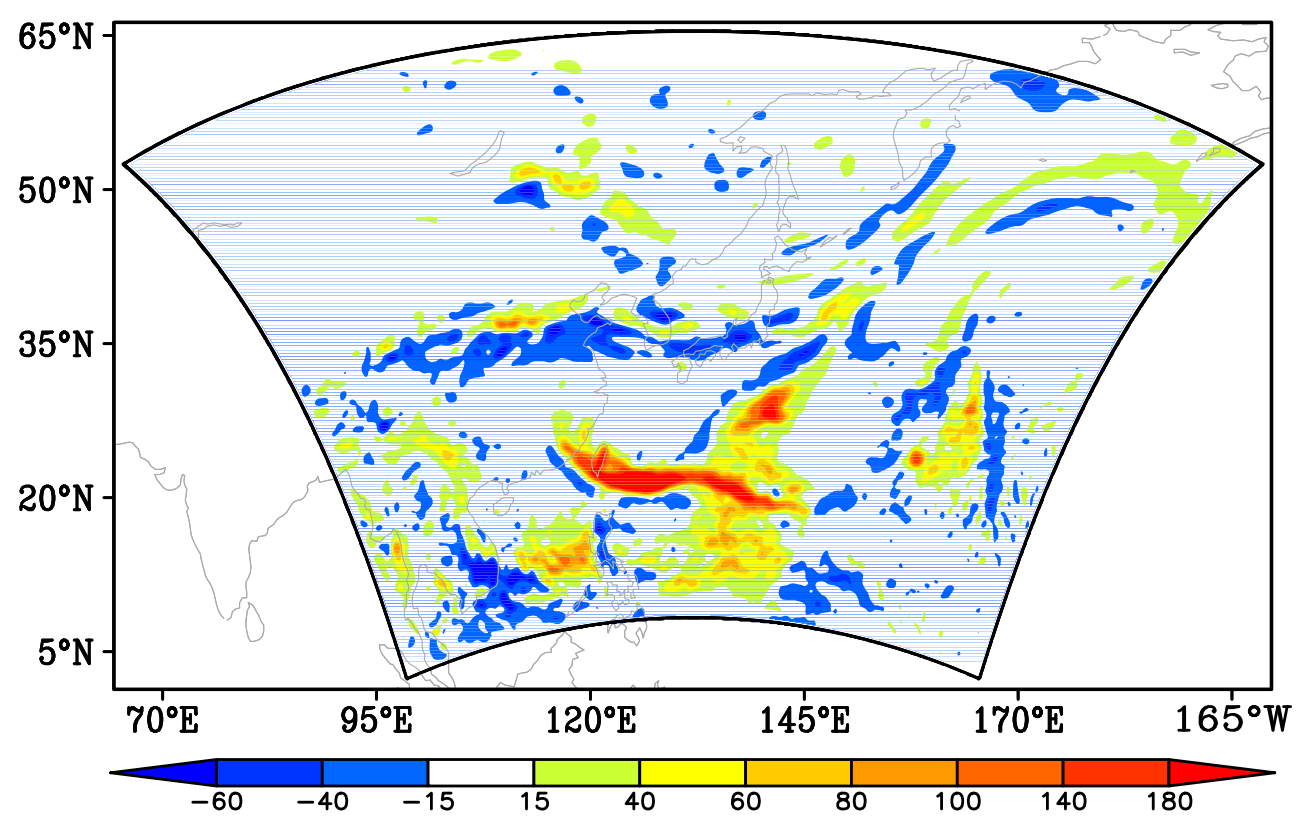


abnormal anticyclonic circulation band that extends from central-eastern China to Pacific Ocean to the east of Japan in the middle and lower troposphere, which is favorable for more hot days in central-eastern China.

Generally, TCs bring huge amounts of heat and water vapor to the middle and high latitudes as they move northwestward, and thus transport and disperse energy to extratropical areas. TC activities are an important factor that affects the transportation, distribution, and budget of global energy (Korty et al. 2008; Pasquero and Emanuel 2008; Jansen and Ferrari 2009; Ha et al. 2013). Moreover, it has been found that TCs have great feedbacks not only on the atmosphere and ocean but also on regional/global climate and climate variability (Sobel and Camargo 2005; Zhong and Hu 2007; Hsu et al. 2008; Sriver 2013). The direct impact of TCs, no matter whether they make landfalls or sweep over the coastal region of eastern China, would bring abundant precipitation and lower temperature in southeastern China. However, the present study emphasizes the "indirect" TC impact on precipitation and hot days by exploring TC feedbacks on the WPSH in the summer, as the influence of TCs on heat waves in Southeastern Australia (Parker et al. 2013).

In addition, it is well known that the meridional displacement of the East Asian circulation in the summer is closely related to the evolution of the Pacific-Japan (PJ) teleconnection pattern on interannual timescale ( $\mathrm{Lu} 2004$; $\mathrm{Lu}$ and $\mathrm{Lin} 2009$; Zhong et al. 2015), which is attributed to the northward propagation of Rossby waves triggered by anomalous convective activities over the tropical WNP (Nitta 1987; Huang and Sun 1992). Furthermore, it is also found that stationary Rossby waves induced by typhoons over the WNP could stimulate the PJ teleconnection pattern (Kawamura and Ogasawara 2006) and vice versa (Choi et al. 2010; Kubota et al. 2016). This explains why strong abnormal meridional circulation develops and displays wave train characteristics in AYs, accompanied by northward propagation of Rossby waves. Therefore, the abnormal meridional circulation can influence the atmospheric circulation in the mid-latitudes (Yamada and Kawamura 2007; Kosaka and Nakamura 2010). In particular, strong convections including the contribution of TCs in the tropical WNP will lead to abnormal descending flows along the latitudes at southern Japan, which will intensify the pressure system there and cause a poleward shift of the WPSH as pointed out by Wang et al. (2019). In other words, while TC activities can directly increase positive vorticity and intensify ascending motions in the middle and lower troposphere along their tracks, frequent TC activities can indirectly increase negative vorticity and intensify descending motions in the mid-latitudes from central-eastern China to the Pacific Ocean to the east of Japan. Such indirect TC impacts can partly make up for the decrease in geopotential height in that region, resulting in a relatively small decrease in geopotential height and an abnormal anticyclonic band in the middle and lower troposphere (Fig. 2c, f).
Funding information This work is financially supported by the National Natural Science Foundation of China (41430426, 41605072, 41505058) and the R\&D Special Fund for Public Welfare Industry (Meteorology) (GYHY201306025).

Open Access This article is distributed under the terms of the Creative Commons Attribution 4.0 International License (http:// creativecommons.org/licenses/by/4.0/), which permits unrestricted use, distribution, and reproduction in any medium, provided you give appropriate credit to the original author(s) and the source, provide a link to the Creative Commons license, and indicate if changes were made.

\section{References}

Alexander LV, Zhang X, Peterson TC, Caesar J, Gleason B, Klein Tank AMG, Haylock M, Collins D, Trewin B, Rahimzadeh F, Tagipour A, Rupa Kumar K, Revadekar J, Griffiths G, Vincent L, Stephenson DB, Burn J, Aguilar E, Brunet M, Taylor M, New M, Zhai P, Rusticucci M, Vazquez-Aguirre JL (2006) Global observed changes in daily climate extremes of temperature and precipitation. $\mathrm{J}$ Geophys Res Atmos 111:1-22

Chen J, Wu R, Wen Z (2012) Contribution of South China Sea tropical cyclones to an Increase in Southern China summer rainfall around 1993. Adv Atmos Sci 29:585-598

Chen X, Zhong Z, Lu W (2017) Association of the poleward shift of East Asian subtropical upper level jet with frequent tropical cyclone activities over the western North Pacific in summer. J Clim 30:55975603

Choi KS, Wu C-C, Cha EJ (2010) Change of tropical cyclone activity by Pacific-Japan teleconnection pattern in the western North Pacific. J Geophys Res 115:1-13

Christopher AD, Simon L-N (2001) The NCAR-AFWA tropical cyclone Bogussing Scheme, A report for the Air Force Weather Agency (AFWA). National Center for Atmospheric Research, Boulder, $\mathrm{p} 13$

Coumou D, Rahmstorf S (2012) A decade of weather extremes. Nat Clim Chang 2:491-496

Diffenbaugh NS, Pal JS, Trapp RJ, Giorgi F (2005) Fine-scale processes regulate the response of extreme events to global climate change. Proc Natl Acad Sci 102:15774-15778

Ding T, Qian W, Yan Z (2010) Changes in hot days and heat waves in China during 1961-2007. Int J Climatol 30:1452-1462

Easterling DR, Evans JL, Groisman PY, Karl TR, Kunkel KE, Ambenje P (2000) Observed variability and trends in extreme climate events: a brief review. Bull Am Meteorol Soc 81:417-425

Fang Y, Jian M (2011) Diagnosis study of persistent heat waves in South China during summer 2003. J Trop Oceanogr 30:30-37. (in Chinese)

Grumm RH (2011) The central European and Russian heat event of JulyAugust 2010. Bull Am Meteorol Soc 92:1285-1296

Ha Y, Zhong Z, Hu Y, Yang XQ (2013) Influences of ENSO on Western North Pacific tropical cyclone kinetic energy and its meridional transport. J Clim 26:322-332

Horton DE, Johnson NC, Singh D, Swain DL, Rajaratnam B, Diffenbaugh NS (2015) Contribution of changes in atmospheric circulation patterns to extreme temperature trends. Nature 522: 465-469

Hsu H-H, Hung C-H, Lo A-K, Wu C-C, Hung C-W (2008) Influence of tropical cyclones on the estimation of climate variability in the tropical western north Pacific. J Clim 21:2960-2975

Hu L, Huang G, Qu X (2017) Spatial and temporal features of summer extreme temperature over China during 1960-2013. Theor Appl Climatol 128:821-833 
Huang R, Sun F (1992) Impacts of the tropical western Pacific on the East Asia summer monsoon. J Met Soc Jpn 70:243-256

IPCC (2007) Climate change 2007: the physical science basis. In: Solomon $\mathrm{S}$ et al (eds) Contribution of working group I to the fourth assessment report of the intergovernment panel on climate change. Cambridge Univ. Press, Cambridge

Jansen M, Ferrari R (2009) Impact of the latitudinal distribution of tropical cyclones on ocean heat transport. Geophys Res Lett 36:150-164

Kalnay E, Kanamitsu M, Kistler R, Collins W, Deaven D, Gandin L, Iredell M, Saha S, White G, Woollen J, Zhu Y, Leetmaa A, Reynolds R, Chelliah M, Ebisuzaki W, Higgins W, Janowiak J, Mo KC, Ropelewski C, Wang J, Jenne R, Joseph D (1996) The NCEP/NCAR 40-Year reanalysis project. Bull Am Meteorol Soc $77: 437-472$

Kawamura R, Ogasawara T (2006) On the role of typhoons in generating $\mathrm{PJ}$ teleconnection patterns over the western North Pacific in later summer. SOLA. 2:37-40

Korty RL, Emanuel KA, Scott JR (2008) Tropical cyclone induced upper ocean mixing and climate: Application to equable climates. J Clim 21:638-654

Kosaka Y, Nakamura H (2010) Mechanisms of meridional teleconnection observed between a summer monsoon system and a subtropical anticyclone part I: the Pacific-Japan pattern. J Clim 23:5085-5108

Kubota H, Kosaka Y, Xie S-P (2016) A 117-year long index of the Pacific-Japan pattern with application to interdecadal variability. Int J Climatol 36:1575-1589

Lee M-H, Ho C-H, Kim J-H (2010) Influence of tropical cyclone landfalls on spatiotemporal variations in typhoon season rainfall over South China. Adv Atmos Sci 27:443-454

Liang M, Wu L (2015) Analysis on features of summer extreme high temperature in eastern China (in Chinese). J Met Sci 35:701-709

Lu R (2004) Associations among the components of the East Asian summer monsoon system in the meridional direction. J Met Soc Jpn 82: $155-165$

Lu R, Lin Z (2009) Role of subtropical precipitation anomalies in maintaining the summertime meridional teleconnection over the Western Pacific and East Asia. J Clim 22:2058-2072

Mendelsohn R, Emanuel K, Chonabayashi S, Bakkensen L (2012) The impact of climate change on global tropical cyclone damage. Nat Clim Chang 2:205-209

Miralles DG, Teuling AJ, Heerwaarden CC, Arellano JV (2014) Megaheatwave temperatures due to combined soil desiccation and atmospheric heat accumulation. Nat Geosci 7:345-349

Nitta T (1987) Convective activities in the tropical western Pacific and their impact on the northern hemisphere summer circulation. J Met Soc Jpn 65:373-390

Parker TJ, Berry GJ, Reeder MJ (2013) The influence of tropical cyclones on heat waves in Southeastern Australia. Geophys Res Lett 40: 6264-6270

Pasquero C, Emanuel K (2008) Tropical cyclones and transient upperocean warming. J Clim 21:149-162

Qian X, Yao YQ, Li JR, Zhou YH, Wang S, Liu LY, Yin J (2012) Analysis of all-China sunshine conditions of site selection for large solar telescopes. Chin J Astron Astrophys 36:445-456
Ren FM, Gleason B, Easterling D (2002) Typhoon impacts on China's precipitation during 1957-1996. Adv Atmos Sci 19:943-952

Ren FM, Wu GX, Dong WJ, Wang XL, Wang YM, Ai WX, Li WJ (2006) Changes in tropical cyclone precipitation over China. Geophys Res Lett 33:131-145

Skamarock WC, Klemp JB, Dudhia J, Gill DO, Barker DM, Wang W, Powers JG (2008) A description of the advanced research WRF version 3. NCAR Technical Note NCAR/TN-475 + STR

Sobel AH, Camargo SJ (2005) Influence of western North Pacific tropical cyclones on their large-scale environment. J Atmos Sci 62:33963407

Soon W, Dutta K, Legates DR, Velasco V, Zhang W (2011) Variation in surface air temperature of China during the 20th century. J Atmos Sol Terr Phys 73:2331-2344

Sriver RL (2013) Observational evidence supports the role of tropical cyclones in regulating climate. Proc Natl Acad Sci 110:1517315174

Sun Y, Zhong Z, Lu W, Hu Y (2014) Why are tropical cyclone tracks over the western North Pacific sensitive to the cumulus parameterization scheme in regional climate modeling? A case study for Megi (2010). Mon Weather Rev 142:1240-1249

Sun Y, Zhong Z, Lan Y, Li T, Chen M, Wan HC, Wang Y, Zhong K (2015) Dependence of the relationship between the tropical cyclone track and western Pacific subtropical high intensity on initial storm size: A numerical investigation. J Geophys Res Atmos 120:1145111467

Tang Q, Xie L, Lackmann GM, Liu B (2013) Modeling the impacts of the large-scale atmospheric environment on inland flooding during the landfall of hurricane Floyd (1999). Adv Meteorol 17:129-133

Wang X, Zhong Z, Hu Y, Yuan H (2010) Effect of lateral boundary scheme on the simulation of tropical cyclone tracks in regional climate model RegCM3. Asia-Pac J Atmos Sci 46:221-230

Wang T, Zhong Z, Sun Y, Wang J (2019) Impacts of tropical cyclones on the meridional movement of the western Pacific subtropical high. Atmos Sci Lett 20:e893. https://doi.org/10.1002/as1.893

Wu G, Chou J, Liu Y, He J (2002) Dynamics of the Formation and Variation of Subtropical Anticyclones (in Chinese). Science Press, Beijing

Yamada K, Kawamura R (2007) Dynamical link between typhoon activity and the PJ teleconnection pattern from early summer to autumn as revealed by the JRA-25 reanalysis. SOLA 3:65-68

Zhang J, Wu L, Ren F, Gui X (2013) Changes in tropical cyclone in China. J Met Soc Jpn 91:585-595

Zhong Z, Hu Y (2007) Impact of tropical cyclones on the regional climate: An East Asian summer monsoon case. Atmos Sci Lett 8:9399

Zhong Z, Tang X, Lu W, Chen Z (2015) The relationship of summertime upper level jet over East Asia and the Pacific-Japan teleconnection. J Met Sci 35:672-683

Publisher's note Springer Nature remains neutral with regard to jurisdictional claims in published maps and institutional affiliations. 